2019-03

\title{
Microbial Community Responses to Vanadium Distributions in Mining Geological Environments and Bioremediation Assessment
}

Zhang, Baogang

http://hdl.handle.net/10026.1/17686

10.1029/2018jg004670

Journal of Geophysical Research: Biogeosciences

American Geophysical Union (AGU)

All content in PEARL is protected by copyright law. Author manuscripts are made available in accordance with publisher policies. Please cite only the published version using the details provided on the item record or document. In the absence of an open licence (e.g. Creative Commons), permissions for further reuse of content should be sought from the publisher or author. 


\section{Microbial Community Responses to Vanadium Distributions in Mining Geological Environments and Bioremediation Assessment}

Baogang Zhang ${ }^{1 *}$, Song Wang1, Muhe Diao², Jie Fu ${ }^{3}$, Miaomiao Xie ${ }^{4}$, Jiaxin Shi', Ziqi Liu', Xuelong Cao ${ }^{1}$, Alistair G.L. Borthwick ${ }^{5}$

${ }^{1}$ School of Water Resources and Environment, MOE Key Laboratory of Groundwater Circulation and Environmental Evolution, China University of Geosciences (Beijing), Beijing 100083, P. R. China

${ }^{2}$ Department of Freshwater and Marine Ecology, Institute for Biodiversity and Ecosystem Dynamics, University of Amsterdam, 1090 GE Amsterdam, The Netherlands

${ }^{3}$ Department of Environmental Science and Engineering, Fudan University, Shanghai 200433, P. R. China

${ }^{4}$ School of Land Science and Technology, China University of Geosciences (Beijing), Beijing 100083, P. R. China

${ }^{5}$ School of Engineering, The University of Edinburgh, The King's Buildings, Edinburgh EH9 3JL, UK

Corresponding author: Baogang Zhang (zbgcugb@gmail.com, baogangzhang@cugb.edu.cn)

Key Points:

- Vanadium distributions in soil, water, and sediment were systematically investigated.

- Microbial communities were distinct in specific matrices.

- Bioremediation by indigenous microorganisms was feasible with long-term cultivation. 


\begin{abstract}
Vanadium mining activities can cause contamination of the surrounding geological environment. Vanadium may exist in multiple matrices due to its migration and transformation, forming interactive relationships; however the linkages between vanadium distributions in multiple matrices and microbial community responses remain largely unknown. Vanadium is a redoxsensitive metal that can be microbiologically reduced and immobilized. To date, bioremediation of vanadium-contaminated environments by indigenous microorganisms has rarely been evaluated. This paper reports a systematic investigation into vanadium distributions and microbial communities in soils, water, and sediment from Panzhihua, China. High vanadium contents of $1130.1 \pm 9.8 \mathrm{mg} \mathrm{kg}^{-1}$ and $0.13 \pm 0.02 \mathrm{mg} \mathrm{L}^{-1}$ were found in surface soil and groundwater. Vanadium in surface water tended to precipitate onto sediments. Microbial communities isolated from similar environments were alike, whereas communities were distinct when compared to different matrices, with relatively lower richness and diversity in groundwater. Proteobacteria was distributed widely and dominated microbial communities within groundwater. Vanadium and additional nutrients significantly affected metal-tolerant bacteria. Long-term cultivation ( $240 \mathrm{~d}$ ) indicated the possibility of vanadium bioremediation by indigenous microorganisms, with increased acid-soluble fraction. This active fraction can potentially release mobile vanadium with shifted redox condition. Vanadium (V) was bioreduced to less toxic, mobile vanadium (IV) primarily by enriched Bacillus and Thauera. This study helps reveal the biogeochemical fate of vanadium in regional geological environments, and suggests a bioremediation pathway via native vanadium-reducing microbes.
\end{abstract}

\title{
1 Introduction
}

Heavy metal pollution of the geological environment is a serious environmental issue (Hochella et al., 2005; Gough et al., 2008; Ran et al., 2015); in recent years, vanadium has gained increasing attention as an emerging contaminant (Yelton et al., 2013; Zhang et al., 2015a). Vanadium is an essential trace element required by both animals and plants, and plays an important role in human health (Rowell et al., 1998; Crans et al., 2004). However, high concentrations of vanadium are harmful to living organisms (Jayawardana et al., 2014). The U.S. American Conference of Governmental Industrial Hygienists has adopted an exposure limit of $0.05 \mathrm{mg} \mathrm{m}^{-3}$ for vanadium as inhalable particulate matter (Assem \& Levy, 2009). Phosphate metabolism can be adversely affected by vanadium (Zhang et al., 2014). Ingestion of vanadium can lead to serious diseases, including pulmonary tumors (Chen \& Liu, 2017). Human beings are known to suffer allergic reactions such as asthma, conjunctivitis, and rhinitis after exposure to vanadium. Lung disease is common among workers engaged in vanadium production (Teng et al., 2006). Vanadium widely exists in the Earth's crust alongside minerals, crude oil, and coal (Huang et al., 2015). Global and European vanadium concentrations in soil typically range between 90 and $60 \mathrm{mg} \mathrm{kg}^{-1}$ (Yang et al., 2014b). In China, the soil background levels of vanadium are estimated at $82 \mathrm{mg} \mathrm{kg}^{-1}$ (Teng et al., 2011). Vanadium enters water naturally through geological weathering of vanadium-containing minerals (Cole et al., 2017). Anthropogenic activities, especially intensive mining of vanadium-bearing minerals, result in excessive amounts of vanadium being released into regional geological environments, causing severe public health issues (Zhang et al., 2012; Chen \& Liu, 2017).

Soil, water, and sediment play crucial roles in providing habitats and nutrient resources to plants, animals, and microorganisms (Repert et al., 2014; Dukes et al., 2018). Vanadium 
contamination of the geological environment is widespread globally, such as in Italy (239 $\mathrm{mg} \mathrm{kg}^{-}$ ${ }^{1}$ in peri-urban soil) (Guagliardi et al., 2018), Germany (90.4 $\mathrm{mg} \mathrm{kg}^{-1}$ in floodplain soil) (Shaheen et al., 2014), Russia (278 $\mathrm{mg} \mathrm{kg}^{-1}$ in soil from nature reserves) (Timofeeva et al., 2018), Egypt (122 $\mathrm{mg} \mathrm{kg}^{-1}$ in soil profile) (Shaheen and Rinklebe, 2018), and South Africa (437 $\mathrm{mg} \mathrm{L}^{-1}$ in mine water) (Kamika and Momba, 2014). Recently, $4794 \mathrm{mg} \mathrm{kg}^{-1}$ vanadium was reported in surface soil samples from the Panzhihua region, Southwestern China, where abundant vanadiumbearing titanomagnetite resources account for $64 \%$ of the vanadium supply in China (Cao et al., 2017). Surface water in this area also contains high concentrations of vanadium, ranging from 0.076 to $0.285 \mathrm{mg} \mathrm{L}^{-1}$ in Jinsha River near a tailing impoundment, exceeding the recommended limit of $0.05 \mathrm{mg} \mathrm{L}^{-1}$ for drinking water sources based on standards of China (Wang et al., 2009). In Rifle, Colorado, USA, vanadium concentration in groundwater reached $0.77 \mathrm{mg} \mathrm{L}^{-1}$ near a tailing impoundment (Ortiz-Bernad et al., 2004). The Rifle site comprises a former vanadium and uranium ore processing facility, and is an Integrated Field Research Challenge site (IFRC) managed by the US Department of Energy (DOE). Remediation efforts, such as pilot-scale in situ biosequestration and acetate-amended field biostimulation, have been found effective at controlling vanadium (Yelton et al., 2013; Xu et al., 2017). Vanadium concentrations of $1620 \mathrm{mg}$ $\mathrm{kg}^{-1}$ have been measured in sediments from a reservoir located near a former vanadium mining facility in Lake Catherine, Arkansas, USA, with low bioavailability attributed to reduced speciation (Nedrich et al., 2018). To date, most studies have focused on vanadium within a specific environmental matrix, and so very little is presently known about the linkages of vanadium distributions in multiple matrices in regional geological environments.

Microorganisms perform vital functions in environmental ecosystems and are sensitive to environmental stress (Batson et al., 2015; Moore et al., 2018). Accumulated vanadium in such matrices can substantially alter microbial communities (Yang et al., 2014a). Decreased microbial richness and diversity in soil, and reduced soil basal respiration have been found to correlate with vanadium pollution (Cao et al., 2017; Xiao et al., 2017). Nevertheless, characteristics of microbial communities with vanadium present in other environmental matrices, such as water and sediment, have rarely been investigated. For remediation, vanadium has to be removed from these matrices to avoid negative ecological impacts. Conventional adsorption is often employed, but can only transfer vanadium in aqueous phase to solid medium, which may lead to secondary pollution (Gao et al., 2017). In addition, there are three oxidation states of vanadium in the natural environment; namely: vanadium (III), vanadium (IV), and vanadium (V) (Carpentier et al., 2003). V(V) is the most toxic, whereas V(IV) is less toxic and can precipitate in near-neutral conditions; thus reduction of $\mathrm{V}(\mathrm{V})$ to $\mathrm{V}(\mathrm{IV})$ is recognized as a promising remediation strategy (Imtiaz et al., 2015). Although traditional chemical/electrochemical reductions can achieve this transformation (Wilson and Weber, 1979; Zhang et al., 2009), their cost-effectiveness is questionable and limits field application.

Microorganisms can reduce V(V) to V(IV) at limited expense (Liu et al., 2017). Microbial V(V) reduction takes place in two ways: respiration of V(V) through electron transfer, and reduction by microbes for detoxification purposes with vanadium binding to reductases of other electron acceptors (Liu et al., 2016). Pure cultures of Geobacter metallireducens, Shewanella oneidensis and methanogens appear to function well in terms of this transformation (Zhang et al., 2014). Mixed anaerobic cultures from wastewater treatment plant also detoxify $\mathrm{V}(\mathrm{V})$ efficiently due to their greater microbial diversity, adaption, and self-evolution (Zhang et al., 2015a). Comparative evaluation of the performance of dissolved organic carbon sources shows that acetate supports highly-efficient V(V) bio-reduction (Liu et al., 2016). Oxidation of 
gaseous and solid electron donors, such as hydrogen and elemental sulfur (Jiang et al., 2018; Zhang et al., 2018), can also be coupled to V(V) bio-reduction without organic residues.

Furthermore, coexisting common electron acceptors in groundwater, such as nitrate and sulfate, can decrease the efficiency of V(V) bio-reduction (Liu et al., 2017). However, most existing studies were carried out in engineered systems, with cultures from wastewater treatment facilities. Although bioremediation of vanadium-contaminated environments by indigenous microorganisms is of particular importance, few studies have been carried out to date.

The present study reports a systematic investigation into vanadium distributions and responses of microbial communities in multiple environmental matrices, including surface soil, vertical soil profile, surface water, sediment, and groundwater. Microorganisms in surface soils and waters were experimentally cultivated with $\mathrm{V}(\mathrm{V})$ stress in a laboratory setting to assess the bioremediation potentials of native microorganisms and to discover functional species. Our results provide a detailed understanding of biogeochemical processes related to vanadium which will promote development of effective future strategies for the bioremediation of vanadiumpolluted environments.

\section{Materials and Methods}

\subsection{Site Description and Sample Collection}

Sampling sites were located in the Panzhihua region $\left(26^{\circ} 05^{\prime}-27^{\circ} 21^{\prime} \mathrm{N}, 101^{\circ} 08^{\prime}-102^{\circ} 15^{\prime}\right.$ E), Sichuan Province, China, at elevation about $1200 \mathrm{~m}$ above sea level. Average temperature ranged from 19.7 to $20.5^{\circ} \mathrm{C}$ and average annual rainfall was $860 \mathrm{~mm}$. Vanadium mining and smelting activities have been conducted in the region since the 1960s. Samples were collected from four different processing stages, including mining plant (MP), concentrator (CO), smelter (SM), and tailing reservoir (TR) (Fig. S1, Supporting Information (SI)) in April 2016. Four surface soil (0 -10 cm layer) samples (MP-SL0, CO-SL0, SM-SL0, TR-SL0) and four corresponding groundwater samples (MP-GW0, CO-GW0, SM-GW0, TR-GW0) were collected. Vertical soil profile samples at depths of 0-10, 10-20, 20-40, 40-60, 60-80 and 80-100 cm (TRS1-6) were extracted in the TR area, within $500 \mathrm{~m}$ of TR-SL0. Two surface water samples were obtained; one from the TR area (TR-SW0), the other from Jinsha River (JS-SW0). Two sediment samples at TR-SD0 and JS-SD0 were also collected. One tailing sample (TR-TL0) was also collected from TR for reference. All samples consisted of five subsamples, mixed thoroughly (Cao et al., 2017). Approximately $1.5 \mathrm{~kg}$ soil/sediment was selected for each solid sample and packaged within polyethylene bags, and $20 \mathrm{~L}$ water was collected for each aqueous sample and stored in polyethylene buckets. All samples reached the laboratory within $48 \mathrm{~h}$ of collection. Samples were stored at $-20^{\circ} \mathrm{C}$ prior to physicochemical and microbial analyses.

\subsection{Physicochemical Analysis}

Soil samples were air-dried at ambient temperature $\left(\sim 20^{\circ} \mathrm{C}\right)$ and sieved through a $2 \mathrm{~mm}$ mesh. $\mathrm{pH}$ (soil:water = 1:2.5) was assessed using HI $3221 \mathrm{pH} / \mathrm{ORP}$ meter (Hanna Instruments Inc., USA). Organic matter (OM), total nitrogen (TN), available phosphorus (AP), and available sulfur (AS) were measured after sieving through a $0.149 \mathrm{~mm}$ mesh (Cao et al., 2017). Briefly, $\mathrm{OM}$ was determined by wet oxidation using $\mathrm{K}_{2} \mathrm{Cr}_{2} \mathrm{O}_{7}$. TN was measured by the Kjeldahl method after digesting with $\mathrm{H}_{2} \mathrm{SO}_{4}$, AP was analyzed using molybdenum antimony spectrophotometry, and AS was monitored by the turbidimetric procedure. Samples were pretreated by microwave digestion (MARS 6, CEM Corp., USA) with aqua regia for measurement of total vanadium and 
other metal ions. The modified three-step Community Bureau of Reference (BCR) sequential extraction method was employed to evaluate vanadium fractions for solid samples with acidsoluble, reducible, oxidizable, and residual phases (Ure et al., 1993). Contents of vanadium and other metal ions in the digested and extracted samples were determined by inductively coupled plasma-mass spectrometry (ICP-MS, Agilent Technologies 7700 Series, USA).

Aqueous samples were filtrated through $0.22 \mu \mathrm{m}$ cellulose acetate syringe filters. $\mathrm{pH}$, total vanadium, and other metal ions were measured by the same instruments as used for the solid samples. Total organic carbon (TOC) was determined by a Total Carbon Analyzer (TOC5000 , Shimadzu, Japan) and $\mathrm{Cl}^{-}, \mathrm{Br}^{-}, \mathrm{NO}_{3}{ }^{-}, \mathrm{SO}_{4}{ }^{2-}$ were quantified by ion chromatography (ICS900, DIONEX, USA).

\subsection{Cultivation of Microorganisms}

Bioremediation of $\mathrm{V}(\mathrm{V})$-contaminated environment by indigenous microorganisms in representative matrices through nutrients amendment was assessed. Four $250 \mathrm{~mL}$ wild-mouth bottles (Beijing Daxiang Glass Factory, China) equipped with rubber plugs were inoculated with $100 \mathrm{~g}$ surface soil samples (MP-SL0, CO-SL0, SM-SL0, TR-SL0). Incubated samples were amended with mineral salt solution containing $750 \mathrm{mg} \mathrm{L}^{-1} \mathrm{C}_{6} \mathrm{H}_{12} \mathrm{O}_{6}$ and $75 \mathrm{mg} \mathrm{L}^{-1} \mathrm{~V}(\mathrm{~V})$ in the form of $\mathrm{NaVO}_{3}$ (Liu et al., 2016). Five $100 \mathrm{~mL}$ serum bottles equipped with rubber plugs were inoculated with concentrated microbes from $8 \mathrm{~L}$ water samples (MP-GW0, CO-GW0, SM-GW0, TR-GW0, TR-SW0). Similar mineral salt solutions containing $750 \mathrm{mg} \mathrm{L}^{-1}$ acetate and $10 \mathrm{mg} \mathrm{L}^{-1}$ V(V) were added. Different salt solutions were employed to form different nutrient supplements and pollutant loadings (Zhang et al., 2014). All bottles were placed in a shaker at $22 \pm 2{ }^{\circ} \mathrm{C}$. Supplements were added every three days, the incubation study lasting a total of 240 days to achieve reproducible performance with stable microbial communities (Cao et al., 2017). At the end of the incubation, $\mathrm{V}(\mathrm{V})$ removals were monitored in three consecutive cycles, a typical cycle comprising $72 \mathrm{~h}$ for the soil-inoculated system and $12 \mathrm{~h}$ for the water-inoculated system. V(V) was quantified by spectrophotometry (Hao et al., 2015). At the end of the cultivation period, microbial communities in all bioreactors were collected and stored at $-80{ }^{\circ} \mathrm{C}$ prior to genomic analysis.

\subsection{Microbial Community Studies}

Genomic DNA from all field samples and incubated samples was extracted using the FastDNA SPIN Kit for Soil (Oiagen, CA, USA) according to manufacturer's instructions. The V4-V5 hypervariable regions of total bacterial 16S rRNA genes were amplified from solid samples (Cao et al., 2017) and the V3-V4 hypervariable regions of total bacterial 16S rRNA genes were amplified from aqueous samples (Liu et al., 2017). DNA sequencing was performed on the Illumina MiSeq platform by Shanghai Majorbio Technology (Shanghai, China). Raw gene sequences obtained from this study were deposited at the NCBI Sequence Read Archive with accession numbers SRP073713, SRP121440, SRP120206, and SRP129751.

Sequences were clustered into operational taxonomic units (OTUs) setting a 0.03 distance limit (equivalent to $97 \%$ similarity) using the MOTHUR program (version v.1.30.1). Rarefaction curves and Alpha-diversity were also generated using MOTHUR (Amato et al., 2013). Bacterial communities were further presented by non-metric multidimensional scaling (NMDS) analysis using the software program PAST (Hammer et al., 2001). NMDS plots were generated based on Bray-Curtis similarities calculated between different samples using the OTU table with OTU 
clustering at the genus level. Redundancy analysis (RDA) was performed to identify relationships between environmental parameters and bacterial groups using the $\mathrm{R}$ software package (vegan 2.4.4).

\section{Results}

\subsection{Vanadium Distributions and Speciation}

\subsubsection{Vanadium Distributions in Multiple Matrices}

The vanadium content in surface soil samples from MP, CO, SM, and TR areas varied significantly (Fig. 1a), and was respectively 1.26, 1.59, 13.8, and 1.63 times that of the soil background value of vanadium in China $\left(82 \mathrm{mg} \mathrm{kg}^{-1}, p<0.05\right)$. Highest vanadium concentration was obtained from SM-SL0, confirming previous findings by Cao et al. (2017). Other metals were also monitored and higher contents of $\mathrm{Zn}$ and $\mathrm{Cr}$ were observed (Table S1 SI); all Zn results from the four sites were above the soil background value $\left(74.2 \mathrm{mg} \mathrm{kg}^{-1}, p<0.01\right)$ in China (Li et al., 2011).

Vanadium in the vertical soil profile from TR first increased and then decreased as the sample depth increased, peaking at TR-S2 (Fig. 1b). Table S1 (SI) also lists values of the other physicochemical indicators, from which it can be seen that $\mathrm{pH}$ was positively related to depth; this is believed to be due to oxidation of ammonium to nitrate in the process of soil air drying to $\mathrm{H}^{+}$in the upper layers ( $\mathrm{Li}$ et al., 2017).

High concentrations of vanadium were detected in aqueous samples (Fig. 1c), most of which exceeded the limit of $0.05 \mathrm{mg} \mathrm{L}^{-1}$ for drinking water sources based on standards of China, except JS-SW0 (Wang et al., 2009). Vanadium concentrations in surface water in the TR area exceeded $0.61 \pm 0.03 \mathrm{mg} \mathrm{L}^{-1}(p<0.01)$, significantly greater than previous studies (Table S2, SI). Higher vanadium contents were also found in sediment (Fig. 1a). Compared to surface water, groundwater showed oligotrophic characteristics with less TOC (Table S3 SI). Higher chromium concentrations were detected, especially in TR-GW0 and SM-GW0.

\subsubsection{Vanadium Speciation in Solid Matrices}

Fractions of vanadium in solid samples were further studied to assess bioavailability. The residual fraction accounted for the highest concentration occurring in surface soils and sediments (Table 1), suggesting that vanadium in solid matrices in this mining region was not bioavailable. In particular, SM-SL0 and TR-SL0 possessed the highest ratios of vanadium in acid-soluble, oxidizable, and reducible fractions $(45.5 \pm 2.6 \%$ and $43.1 \pm 1.3 \%, p<0.05)$. The residual fraction had the largest concentration, followed by oxidizable reducible, and acid-soluble fractions in the vertical soil profile, implying that vanadium speciation remains nearly constant with increasing soil depth.

\subsection{Microbial Community in Multiple Matrices}

\subsubsection{Richness, Diversity and Structure}

Microbial richness, diversity, and structure of surface soils were then investigated. Detected OTUs ranged from 597 to 867 ( $p<0.05$, Table S4 SI). SM-SL0 possessed the greatest richness and diversity as reflected by rarefaction curves (Fig. S2a SI), and Shannon and Simpson 
indexes. Similar community compositions at phylum level were observed, dominated by Bacteroidetes (20.6\%-37.9\%), Proteobacteria (9.6\%-37.8\%), and Firmicutes (6.9\%-37.4\%) $(p<$ 0.05) (Fig. S3a SI). Microbes responsible for metal bio-transformations were present at genus level (Fig. 2a). Geobacter, Pseudomonas and Comamonas existed in all surface soil samples. Significant accumulation of other genera occurred in specific samples, for instance, Zoogloea in MP-SL0 (15.7\%) and Trichococcus in CO-SL0 (17.1\%).

Microbial richness in the vertical soil profile first increased slightly and then decreased with increasing depth, peaking in TR-S3 (Fig. S2b, Table S4 SI). The Shannon index suggested generally decreased microbial diversity as the depth increased. Samples of vertical soil profile exhibited similar community compositions at phylum level (Fig. S3b SI). Apart from the dominant Proteobacteria (11.7\%-22.6\%) in surface soils, Actinobacteria $(22.2 \%-39.0 \%)$ and Acidobacteria $(15.2 \%-27.4 \%)$ also predominated $(p<0.05)$. Microbes related to heavy metals were also revealed at genus level (Fig. 2b). Actinobacteria species were abundant in all vertical soil profile samples, whereas Streptomyces was observed in the deeper soil samples.

Relatively lower microbial abundances were observed in groundwater than in soils (Fig. S2c, Table S4 SI), due to the oligotrophic characteristics of the aquifers, especially for MP-GW0, with TOC of $0.94 \pm 0.05 \mathrm{mg} \mathrm{L}^{-1}$ and $\mathrm{NO}_{3}{ }^{-}$of $8.54 \pm 0.11 \mathrm{mg} \mathrm{L}^{-1}$. Microbial diversity showed similar tendencies with microbial richness, with highest Shannon index for TR-GW0 and lowest for MP-GW0. Proteobacteria (58.0\%-89.1\%) dominated all groundwater samples at phylum level $(p<0.05)$ (Fig. S3c SI), consistent with accumulation of Proteobacteria in soil. Bacteroidetes also accounted for a large portion (29.1\%) of microbes in SM-GW0, consistent with its appearance in SM-SL0. Microbes active in metal biogeochemical processes were found at genus level (Fig. 2c), including Novosphingobium in all groundwater samples, and most abundant in MP-GW0 (74.9\%). Flavobacterium and Acinetobacter were dominant in SM-GW0. Sphingobium was abundant in TR-GW0 (21.9\%).

Fewer OTUs were found in surface water samples compared to sediments (Fig. S2d, Table S4 SI), suggesting decreased microbial richness in the aqueous matrix. TR-SW0 had lower microbial richness than TR-GW0 possibly due to direct contact with tailings. The Shannon index suggested microbes were more diverse in sediments than in surface water. Proteobacteria and Actinobacteria appeared in all samples at phylum level (Fig. S3d SI), at relatively larger abundance in surface water than sediments. Metal-related microbes were also observed (Fig. 2d). Exiguobacterium was abundant in JS-SD0 (11.5\%), but decreased to $0.02 \%$ in JS-SW0. Synechococcus was only detected in TR-SW0, whereas Cyanobacteria was found in TR-SD0.

\subsubsection{Similarities and Influences of Environmental Parameters}

Similarities between bacterial communities were visualized by NMDS (Fig. 3a). Interestingly, bacterial communities were distinct among different matrices in vanadium-mining geological environments, whereas they showed certain similarities in the same matrix. Samples from surface soils, vertical soil profile, and groundwater clustered separately. There were also similarities in samples from the same site, for example, JS-SW0 and JS-SD0, both of which were taken from the same location in Jinsha River.

RDA was performed to reveal influences of environmental parameters on bacteria involved in metal tolerance and biotransformation. In solid matrices, nutrients factors including $\mathrm{OM}, \mathrm{TN}$, and available $\mathrm{S}$ were identified to have important influences (Fig. 3b). The first two 
axes of the RDA explained $48.1 \%$ and $23.0 \%$ of variations in microbial data. Vanadium was positively associated with Trichococcus and also affected abundance of Geobacter and Comamonas. In aqueous matrices, $\mathrm{pH}$ and nutrients, such as $\mathrm{TOC}$ and $\mathrm{NO}_{3}{ }^{-}$, had significant influences on the presence of metal-related bacteria (Fig. 3c). Vanadium had a major impact on the abundance of Synechococcus.

\subsection{Behavior of Cultivated Indigenous Microorganisms}

\subsubsection{V(V) Removals and Reduction Products}

Gradual decreases in $\mathrm{V}(\mathrm{V})$ with time were observed in three consecutive cycles for all cultivated systems (Fig. 4a, Fig. 4b). Removal efficiencies of V(V) ranged from $65.2 \pm 1.9 \%$ to $98.7 \pm 3.6 \%(p<0.05)$ in a typical cycle $(72 \mathrm{~h})$ in soil-inoculated bioreactors, with removal rates from $0.68 \pm 0.07$ to $0.97 \pm 0.09 \mathrm{mg} \mathrm{L}^{-1} \cdot \mathrm{h}^{-1}(p<0.05)$, whereas $78.0 \pm 3.5 \%$ to $88.3 \pm 3.7 \%$ of $\mathrm{V}(\mathrm{V})(p<0.05)$ was removed in a typical cycle $(12 \mathrm{~h})$ by microbes in water, with removal rates from $0.59 \pm 0.02$ to $0.74 \pm 0.03 \mathrm{mg} \mathrm{L}^{-1} \cdot \mathrm{h}^{-1}(p<0.05)$. After microbially mediated $\mathrm{V}(\mathrm{V})$ reduction in soil-inoculated reactors, the percentage of acid-soluble fraction for vanadium in cultivated soil increased (Fig. 4c) owing to reduction products.

When $\mathrm{V}(\mathrm{V})$ was reduced by microbes from the inoculated water samples, blue precipitates appeared concomitantly over the incubation period. Fig. 4d shows the highresolution spectrum of $\mathrm{V} 2 \mathrm{p}$ where a sub-band is located at about $516.3 \mathrm{eV}$ corresponding to V(IV) (Zhang et al., 2018; Cai et al., 2017), the main component of mineral sincosite $\left[\mathrm{CaV}_{2}\left(\mathrm{PO}_{4}\right)_{2}(\mathrm{OH})_{4} \cdot 3 \mathrm{H}_{2} \mathrm{O}\right]$ in bioreactors (Qiu et al., 2017).

\subsubsection{Evolution of Microbial Community}

The microbial community changed significantly after cultivation. More abundant microbes were found in all soil-inoculated bioreactors compared with the corresponding original samples, as reflected by rarefaction curves in Fig. S4a (SI) and richness indexes in Table S5 (SI). The Shannon index also indicated that microbes after cultivation became more diverse. In comparison, the richness and diversity of microbes in water samples further decreased after cultivation (Fig. S4b, Table S5 SI). NMDS results indicated that bacterial communities became similar after long-term cultivation with vanadium and nutrients (Fig. S4c, Fig. S4d SI).

Functional species related to detoxifying V(V) increased in abundance during cultivation. For soil-inoculated bioreactors (Fig. 5a), previously detected V(V) reducers such as Geobacter were found to decrease with enriched Bacillus, especially in MP-SL1 (2.8\%). Previously identified Streptomyces in the vertical soil profile accumulated significantly, especially in COSL1. Other heavy-metal resistant microbes were also detected, such as Lysobacter, Microvirga and Ramlibacter.

Turning to the microbes in water samples, the functional species accumulated significantly with larger relative abundance of microbes after cultivation; however, we observed a decrease in previously detected metal-tolerant bacteria such as Acinetobacter due to the high concentrations of V(V) (Fig. 5b). Newly observed Longilinea and enriched Pseudomonas were detected with large abundance after cultivation, especially in SM-GW1 and in TR-SW1, respectively. Notably, the abundance of the Fe(III) reducing microbe Thauera increased considerably in all cultivated systems, particularly in CO-GW1, Rhodococcus exhibited higher 
relative abundance after cultivation, especially in TR-GW1, and Brevundimonas also increased in MP-GW1.

\section{Discussion}

\subsection{Linkages of Vanadium Distributions in Geological Environments}

Intensive anthropogenic activities have directly contributed to the occurrences and linkages of vanadium in mining geological environments. Dusts containing residual vanadium are produced concomitantly during mining, smelting, and disposal processes and enter the soil through nature weathering processes such as drying and rewetting (Vicars \& Sickman, 2011; Yang et al., 2014b). Ash in TR (TR-TL0) also possesses abundant vanadium (6932.1 $\pm 15.3 \mathrm{mg}$ $\mathrm{kg}^{-1}$ ) and could be a potential source of vanadium release into the environment. This suggests that severely contaminated surface soil is the primary sink of vanadium in Panzhihua, especially in SM, implying that remediation of smelting areas should be a priority. Given that polymetallic ores are used in Panzhihua region, it is most likely that the detected $\mathrm{Zn}$ and $\mathrm{Cr}$ originated from mining activities. In this case, combined pollution characteristics should be considered when remediation is implemented. Higher contents of vanadium in surface soil layers in the vertical soil profile provided evidence that vanadium originated from atmospheric dry deposition and precipitation (Yang et al., 2017). Although the strong adsorption proprieties of soil could reduce infiltration to a certain extent (Qu et al., 2016), concentration of vanadium at depths of 80-100 $\mathrm{cm}$ still exceeded the soil background value of vanadium in China $\left(82 \mathrm{mg} \mathrm{kg}^{-1}\right)$, implying that strong migration took place when vanadium entered subsurface soil. Moreover, soil could be a source of vanadium in other matrices due to migration of vanadium. Such movement of vanadium could pose significant difficulties to remediation engineering and could be a potential threat to groundwater quality.

Although bioavailability of vanadium in solid matrices had been previously observed in Panzhihua (Cao et al., 2017), local mining activities have increased the bioavailability of vanadium compared to that of vanadium-bearing titanomagnetite. Acid-soluble fraction appeared in all surface soil and in TR-TL0; this fraction is the most active and readily dissolves during rain events (Wang et al., 2009; Jayawardana et al., 2014). The incidence of acid rain events in China is currently increasing (reaching third in the world) (Yu et al., 2017) and so dissolution of vanadium from surface soils is of primary concern. Notably, vanadium in surface soils of CO and TR had greater bioavailability; active fractions have potential geochemical activity that can be transformed into bioavailable vanadium. For instance, reduction of Fe (hydr)oxides under low $\mathrm{E}_{\mathrm{H}}$ have led to release of associated vanadium (Shaheen et al., 2014; Shaheen et al., 2016). Nevertheless, geochemical processes taking place in our study have reduced bioavailable potentials, for example: decreased ratios of acid-soluble, oxidizable, and reducible fractions observed in sediment samples. In the vertical soil profile, the bioavailability of vanadium decreased with depth, potentially due to reduced vanadium fixation by exchangeable bound fractions through surface sorption or surface precipitation (Tokalığlu \& Kartal, 2005) lowering groundwater contamination.

Surface water could be a sink of vanadium, thus affecting distributions of vanadium in other matrices. The high concentrations of vanadium in surface water in the TR could have derived from tailings leaching (Yang et al., 2014b). Infiltration of vanadium in TR-SW0 to groundwater could be due to the observed higher concentration of vanadium in TR. Vanadium 
concentrations in the Jinsha River decreased from a maximum of $0.285 \mathrm{mg} \mathrm{L}^{-1}$ (Wang et al., 2009 ) to $0.013 \pm 0.002 \mathrm{mg} \mathrm{L}^{-1}$ (present study, $p<0.01$ ), implying sedimentation because $\mathrm{V}(\mathrm{V})$ is precipitated through microbial metabolism under anoxic conditions and adsorbed onto suspended particles (Zhang et al., 2015b). As the redox potentials fluctuate, vanadium may desorb and remobilize (Shaheen et al., 2016). Apart from anthropogenic activities, excessive vanadium in groundwater could result from geological weathering of vanadium-containing minerals, noting that the Panzhihua region possesses rich reserves of vanadium-bearing titanomagnetite where vanadium can be released into groundwater through water-rock interaction (Wright \& Belitz, 2010).

Our results have revealed the linkages of vanadium distributions in the Panzhihua region; however, gaps in our knowledge of these relationships still exist for other vanadiumcontaminated sites. For example, research at the Rifle site, Colorado, USA, focused on vanadium in groundwater, and did not assess other matrices such as soil (Yelton et al., 2013). Vanadium in European soils (i.e. Germany and Italy) was researched (Shaheen et al., 2014; Guagliardi et al., 2018), however, surrounding water contamination was not investigated. The present study emphasizes the importance of comprehensive investigations into vanadium distributions in geological matrices due to inherent interactions driven by geological activities. Such investigations could then facilitate successful bioremediation.

\subsection{Microbial Community Responses}

Accumulation of vanadium within the environment caused metal-tolerant microbial species to increase. Bacteroidetes, Proteobacteria, and Firmicutes that dominate surface soils are frequently involved in reduction of V(V) (Zhang et al., 2015a). Identified Geobacter and Pseudomonas immobilized V(V) through bio-reduction (Ortiz-Bernad et al., 2004; Mirazimi et al., 2015). Comamonas can transfer Se(VI) to selenium nanoparticles (Zheng et al., 2014). Zoogloea and Trichococcus are capable of reducing Cr(VI) to $\mathrm{Cr}$ (III) (Solisio et al., 1998; Liu et al., 2017). These members of the microbial community accumulated in our study and were also found in the vanadium-contaminated environment (Cao et al., 2017). They might participate in $\mathrm{V}(\mathrm{V})$ reduction because vanadium is a redox-sensitive metal similar to selenium and chromium (Jiang et al., 2018). As for the vertical soil profile, Acidobacteria that accounted for a large proportion of the microbial population that can adapt to vanadium-polluted environments (Cao et al., 2017). The abilities of Actinobacteria species to reduce $\mathrm{Cr}(\mathrm{VI})$ and Streptomyces to remove chromium have been demonstrated previously (Polti et al., 2014). These two species also appeared with large relative abundances in our subsurface soil samples from the Panzhihua region. They might be capable of reducing $\mathrm{V}(\mathrm{V})$ because most reported $\mathrm{Cr}(\mathrm{VI})$ reducers could bio-reduce V(V) with less toxicity (Wang et al., 2018). Regarding groundwater, Novosphingobium which appeared in all groundwater samples is known to metabolize cobalt (Raghu et al., 2008). Novosphingobium could also be involved in V(V) removal through dissimilatory metal-reduction. Flavobacterium and Acinetobacter can remove heavy metal removals (Kumar et al., 2011), and Sphingobium can tolerate toxic metals (Wang et al., 2013). These three species also appeared abundantly in our groundwater samples and could also contribute to vanadium removal through similar biosorption. There were common microbes in samples from the same site; for example, Bacteroidetes appeared in abundance in both JS-SW0 and JS-SD0. However, these commonalities weakened at genus level, with respective metalrelated microbes. It has previously been established that Synechococcus tolerates copper (Stuart et al., 2013), and Exiguobacterium and Cyanobacteria reduce $\mathrm{Cr}(\mathrm{VI})$ and $\mathrm{Fe}(\mathrm{III})$ (Mohapatra et 
al., 2017; Xu et al., 2016). These bacteria were also present in our surface water and sediment samples. Vanadium is moderately toxic, with toxicity less than chromium and copper, and so metal-tolerant bacteria could also exhibit tolerance to high concentrations of vanadium (Aihemaiti et al., 2018). The metal-tolerant microbial communities associated with our samples have the ability to tolerate, reduce, and immobilize V(V).

Vanadium environmental contamination influenced microbial communities. In surface soils, the greatest vanadium content, and microbial richness and diversity were found in SMSL0, indicating that the presence of vanadium might stimulate growth and proliferation of specific microbial communities. Moreover, both microbial richness and diversity were positively related to vanadium concentration in groundwater. RDA also suggests that concentrations of vanadium shape the structure of metal tolerant microbes, consistent with results from similar research in the Panzhihua region (Cao et al., 2017). Our findings suggest that the addition of nutrient supplements could enhance functional species for efficient bioremediation (Callister et al., 2010; Yelton et al., 2013). Due to the varying geological conditions, metal tolerant microbial communities differ. For example: Comamonadaceae appeared abundantly in aquifer samples collected from the Rifle site, Colorado, USA (Yelton et al., 2013). Therefore, the results from the present study offer helpful insights into the biogeochemical fate of vanadium in vanadiumcontaminated sites with specific microbial communities.

\subsection{Evaluation of Microbial Remediation}

$\mathrm{V}(\mathrm{V})$ in contaminated systems could be reduced by indigenous microorganisms via the addition of a carbon source, indicating the potential for bioremediation. Moreover, the obtained $\mathrm{V}(\mathrm{V})$ bioremediation efficiencies $\left(65.2 \pm 1.9 \%\right.$ to $98.7 \pm 3.6 \%$ of $75 \mathrm{mg} \mathrm{L}^{-1}$ within $72 \mathrm{~h}$ in soilinoculated bioreactors and $78.0 \pm 3.5 \%$ to $88.3 \pm 3.7 \%$ of $10 \mathrm{mg} \mathrm{L}^{-1}$ within $12 \mathrm{~h}$ by microbes in waters) exhibited advantages in comparison to results from pure cultures and field tests. For example, 30 days were required to reduce $2 \mathrm{mM} \mathrm{V(V)}$ by mesophilic and thermophilic methanogens (Zhang et al., 2014), whereas $99 \%$ of $6 \mathrm{mM} \mathrm{V(V)}$ in an aquifer were removed in 22 $\mathrm{d}$ with acetate bio-stimulation (Yelton et al., 2013). Notably, V(V) was reduced relatively quickly by microbes from matrices that were heavily contaminated, such as SM-SL0 (Fig. 4a) and TR-GW0 (Fig. 4b), because microbial communities in these matrices had adapted to high levels of vanadium. In water samples, less mobile and toxic V(IV) formed from V(V) bioreduction, alleviating water contamination by indigenous microorganisms. However, reduction products formed an acid-soluble fraction within soil. This active fraction could release mobile vanadium when the redox condition shifts, providing a secondary source of microbial-mediated contamination.

Soil microorganisms were stimulated by nutrient addition, with increased richness and diversity occurring after cultivation (Fig. S4a, Table S5 SI)), despite the presence of vanadium at higher concentrations. Vanadium played an important role in shaping microbial community structure, especially for microbes in water, as accumulated functional species related to V(V) reduction at genus level after incubation differed from those in the inocula (Fig. 5b). Microbial communities converged after cultivation (Fig. S4c, Fig. S4d SI). Similar microbial communities after cultivation had been observed in vanadium-loaded soils (Cao et al., 2017); it was hypothesized that long-term incubation with the same substrate could lead to aggregation of microbial communities (Yang et al., 2014b). 
Metal-tolerant microbes in our samples were susceptible to high concentrations of $\mathrm{V}(\mathrm{V})$ and were replaced over the incubation period, suggesting a succession of microbial communities had occurred. For soil-inoculated bioreactors, Bacillus was significantly enriched after cultivation, and has also been detected at a high-metal content site in Guanajuato, Mexico, where it was found capable of removing V(V) (Rivas-Castillo et al., 2017). Enriched Bacillus could therefore play a direct role of reducing V(V) in our soil-inoculated systems. Other enriched species found in the systems considered herein have previously been reported capable of tolerating heavy metals, such as the ctinobacterial strain Streptomyces in marine sediments which tolerates Ni (Undabarrena et al., 2017), Lysobacter which has genes resistant to Co (Puopolo et al., 2016), Microvirga from the arid Taklamakan desert which strongly resists $\mathrm{Pb}$ through intracellular precipitations (Luo et al., 2014), and Ramlibacter from chromite ore processing residue-contaminated soils which is resistant to $\mathrm{Cr}$ (Min et al., 2017). These metal-tolerant species accumulated abundantly after long-term incubation, and were probably tolerant to vanadium because vanadium is less toxic than the afore-mentioned metals. In water-inoculated bioreactors, Longilinea and Pseudomonas were newly observed, both of which are capable of $\mathrm{V}(\mathrm{V})$ reduction. Similar microorganisms have been identified in groundwater bioremediation efforts as a result of organic carbon source addition (Liu et al., 2017; Zhang et al., 2015a). Thauera is able to reduce Fe(III) under anaerobic conditions (Ma et al., 2015). Rhodococcus in leachate-contaminated soil can reduce $\mathrm{Pb}(\mathrm{IV})$ (Emenike et al., 2016), and Brevundimonas in subtropical paddy soils of China is known to participate in Fe(III) reducing processes (Peng et al., 2016). These species were also enriched in our inoculated bioreactors, which could also function in $\mathrm{V}(\mathrm{V})$ reduction through a similar electron transport pathway (Hao et al., 2018). In particular, functional species for $\mathrm{V}(\mathrm{V})$ reduction were more abundant in, and even dominated microbial communities within water compared to soil, implying that bioremediation could be more efficient for $\mathrm{V}(\mathrm{V})$-contaminated water environments by indigenous microorganisms. Addition of vanadium could result in decreasing microbial richness and diversity in groundwater, as suggested by Yelton, et al., (2013). Enriched functional bacteria varied due to different initial microbial community structure, geological conditions, and applied electron donors. However, the present study indicates the possibility of immobilizing $\mathrm{V}(\mathrm{V})$ through in situ bio-stimulation of indigenous microorganisms by providing sufficient electron donors. During practical implementation, optimal electron donors could be mixed thoroughly with solid matrices or injected directly into groundwater to reduce $\mathrm{V}(\mathrm{V})$ in the geological environment by indigenous microorganisms. Other factors, such as nutrient addition, geological structure, and operating conditions, should also be taken into account.

\section{Conclusions}

Vanadium distribution from multiple matrices in Panzhihua region, China, was systematically studied. Vanadium contents in all surface soils and the vertical soil profile invariably exceeded the soil background value of vanadium in China ( $\left.82 \mathrm{mg} \mathrm{kg}^{-1}\right)$. High vanadium concentrations in groundwater were also detected, whereas vanadium in surface water tended to precipitate onto sediments. Microbial community structures from different environmental matrices were diverse, with relatively lower richness and diversity found in water samples. Proteobacteria were widespread, and dominated microbial communities in groundwater. Metal-tolerant bacteria were associated with vanadium content and nutrients. V(V) was successfully bio-reduced to less toxic V(IV) by indigenous microorganisms after $240 \mathrm{~d}$ cultivation. The structure of microbial communities changed considerably during cultivation. 
Enrichments of Bacillus and Thauera could be responsible for bio-transformations of V(V) to V(IV).

\section{Acknowledgments}

This research work was supported by the National Natural Science Foundation of China (NSFC) (No. 91647115, No. 41672237) and Beijing Nova Program (No. Z171100001117082). We are grateful for the free provision of NCBI Sequence Read Archive database of microbial data at https://www.ncbi.nlm.nih.gov/sra. Chemical data depicted in the Figures are given in the Supporting Information. There authors declare no conflicts of interest.

\section{References}

Aihemaiti, A., Jiang, J., Li, D., Liu, N., Yang, M., Meng, Y., \& Zou, Q. (2018). The interactions of metal concentrations and soil properties on toxic metal accumulation of native plants in vanadium mining area. Journal of Environmental Management, 222(15), 216-226. https://doi.org/ 10.1016/j.jenvman.2018.05.081

Amato, K. R., Yeoman, C. J., Kent, A., Righini, N., Carbonero, F., Estrada, A., \& Leigh, S. R. (2013). Habitat degradation impacts black howler monkey (Alouatta pigra) gastrointestinal microbiomes. The ISME Journal, 7(7), 1344-1353. https://doi.org/10.1038/ismej.2013.16

Assem, F. L., \& Levy, L. S. (2009). A review of current toxicological concerns on vanadium pentoxide and other vanadium compounds: Gaps in knowledge and directions for future research. Journal of Toxicology and Environmental Health, Part B: Critical Reviews, 12(4), 289-306. https://doi.org/10.1080/10937400903094166

Batson, J., Noe, G. B., Hupp, C. R., Krauss, K. W., Rybicki, N. B., \& Schenk, E. R. (2015). Soil greenhouse gas emissions and carbon budgeting in a short-hydroperiod floodplain wetland. Journal of Geophysical Research: Biogeosciences, 120, 77-95. https://doi.org/10.1002/2014JG002817

Cai, R. Q., Zhang, B. G., Shi, J. X., Li, M., \& He, Z. (2017). Rapid photocatalytic decolorization of methyl orange under visible light using $\mathrm{VS}_{4} /$ carbon powder nanocomposites. $A C S$ Sustainable Chemistry \& Engineering, 5, 7690-7699.

https://doi.org/10.1021/acssuschemeng.7b01137

Callister, J. S., Wilkins, M. J., Nicora, C. D., Williams, K. H., Banfield, J. F., VerBerkmoes, N. C., Hettich, R. L., N'Guessan, L., Mouser, P. J., Elifantz, H., Smith, R. D., Lovley, D. R., Lipton, M. S., \& Long, P. E. (2010). Analysis of biostimulated microbial communities from two field experiments reveals temporal and spatial differences in proteome profiles. Environmental Science \& Technology, 44, 8897-8903. https://doi.org/ 10.1021/es101029f

Cao, X. L., Diao, M. H., Zhang, B. G., Liu, H., Wang, S., \& Yang, M. (2017). Spatial distribution of vanadium and microbial community responses in surface soil of Panzhihua mining and smelting area, China. Chemosphere, 183, 9-17. https://doi.org/10.1016/j.chemosphere.2017.05.092

Carpentier, W., Sandra, K., Smet, D. I., Brige, A., Smet, D. L., \& Van Beeumen, J. (2003). Microbial reduction and precipitation of vanadium by Shewanella oneidensis. Applied and Environmental Microbiology, 69(6), 3636-3639. https://doi.org/10.1128/AEM.69.6.36363639.2003 
Chen, G. D., \& Liu, H. Z. (2017). Understanding reduction kinetics of aqueous vanadium(V) and transformation products using rotating ring-disk electrode. Environmental Science \& Technology, 51, 11643-11651. https://doi.org/10.1021/acs.est.7b02021

Cole, D. B., Zhang, S., \& Planavsky, N. J. (2017). A new estimate of detrital redox-sensitive metal concentrations and variability in fluxes to marine sediments. Geochimica et Cosmochimica Acta, 215, 337-353. https://doi.org/10.1016/j.gca.2017.08.004

Crans, D. C., Smee, J. J., Gaidamauskas, E., \& Yang, L. Q. (2004). The chemistry and biochemistry of vanadium and the biological activities exerted by vanadium compounds. Chemical Reviews, 104(2), 849-902. https://doi.org/10.1021/cr020607t

Dukes, D., Gonzales, H. B., Ravi, S., Grandstaff, D. E., Van Pelt, R. S., Li, J., \& Sankey, J. B. (2018). Quantifying postfire aeolian sediment transport using rare earth element tracers. Journal of Geophysical Research: Biogeosciences, 123. https://doi.org/10.1002/2017JG004284

Emenike, C. U., Agamuthu, P., \& Fauziah, S. H. (2016). Blending Bacillus sp., Lysinibacillus sp. and Rhodococcus sp. for optimal reduction of heavy metals in leachate contaminated soil. Environmental Earth Sciences, 75(1), 26. https://doi.org/ 10.1007/s12665-015-4805-9

Fiorentino, C. E., Paoloni, J. D., Sequeira, M. E., \& Arosteguy, P. (2007). The presence of vanadium in groundwater of southeastern extreme the pampean region Argentina Relationship with other chemical elements. Journal of Contaminant Hydrology, 93(1), 122-129. https://doi.org/10.1016/j.jconhyd.2007.02.001

Gao, Y., Jiang, J., Tian, S., Li, K., Yan, F., Liu, N., Yang, M., \& Chen, X. (2017). BOF steel slag as a low-cost sorbent for vanadium (V) removal from soil washing effluent. Scientific Reports, 7, 11177. https://doi.org/10.1038/s41598-017-11682-3

Gough, H. L., Dahl, A. L., Tribou, E., Noble, P. A., Gaillard, J. F., \& Stahl, D. A. (2008). Elevated sulfate reduction in metal-contaminated freshwater lake sediments. Journal of Geophysical Research: Biogeosciences, 113, G04037. https://doi.org/10.1029/2008JG000738

Guagliardi, I., Cicchella, D., Rosa, R. D., Ricca, N., \& Buttafuoco, G. (2018). Geochemical sources of vanadium in soils: Evidences in a southern Italy area. Journal of Geochemical Exploration, 184, 358-364. https://doi.org/10.1016/j.gexplo.2016.11.017

Hammer, Ø., Harper, D. A. T., \& Ryan, P. D. (2001). Paleontological statistics software package for education and data analysis. Palaeontologia Electronica, 4(1), 1-9.

Hao, L. T., Zhang, B. G., Cheng, M., \& Feng, C. P. (2016). Effects of various organic carbon sources on simultaneous $\mathrm{V}(\mathrm{V})$ reduction and bioelectricity generation in single chamber microbial fuel cells. Bioresource Technology, 201, 105-110. https://doi.org/10.1016/j.biortech.2015.11.060

Hao, L. T., Zhang, B. G., Feng, C. P., Zhang, Z. Y., Lei, Z. F., Shimizu, K., Cao, X. L., Liu, H., \& Liu, H. P. (2018). Microbial vanadium (V) reduction in groundwater with different soils from vanadium ore mining areas. Chemosphere, 202, 272-279. https://doi.org/10.1016/j.chemosphere.2018.03.075

Hao, L. T., Zhang, B. G., Tian, C. X., Liu, Y., Shi, C. H., Cheng, M., \& Feng, C. P. (2015). Enhanced microbial reduction of vanadium (V) in groundwater with bioelectricity from 
microbial fuel cells. Journal of Power Sources, 287, 43-49.

https://doi.org/10.1016/j.jpowsour.2015.04.045

Hochella, M. F., Moore, J. N., Putnis, C. V., Putnis, A., Kasama, T., \& Eberl, D. D. (2005). Direct observation of heavy metal-mineral association from the Clark Fork River Superfund Complex: Implications for metal transport and bioavailability. Geochimica et Cosmochimica Acta, 69(7), 1651-1663. https://doi.org/10.1016/j.gca.2004.07.038

Huang, J. H., Huang, F., Evans, L., \& Glasauer, S. (2015). Vanadium: Global (bio)geochemistry. Chemical Geology, 417, 68-89. https://doi.org/10.1016/j.chemgeo.2015.09.019

Imtiaz, M., Rizwan, M. S., Xiong, S., Li, H., Ashraf, M., Shahzad, S. M., \& Tu, S. (2015). Vanadium, recent advancements and research prospects: A review. Environment International, 80, 79-88. https://doi.org/10.1016/j.envint.2015.03.018

Jayawardana, D. T., Pitawala, H. M. T. G. A., \& Ishiga, H. (2014). Geochemical evidence for the accumulation of vanadium in soils of chronic kidney disease areas in Sri Lanka.

Environmental Earth Sciences, 73(9), 5415-5424. https://doi.org/10.1007/s12665-014-3796-2

Jiang, Y. F., Zhang, B. G., He, C., Shi, J. X., Borthwick, A. G. L., \& Huang, X. Y. (2018). Synchronous microbial vanadium $(\mathrm{V})$ reduction and denitrification in groundwater using hydrogen as the sole electron donor. Water Research, 141, 289-296. https://doi.org/ 10.1016/j.watres.2018.05.033

Kamika, I., \& Momba, M. N. B. (2014). Microbial diversity of Emalahleni mine water in south africa and tolerance ability of the predominant organism to vanadium and nickel. PLoS ONE, 9(1), e86189. https://doi.org/10.1371/journal.pone.0086189

Kumar, A., Bisht, B. S., \& Joshi, V. D. (2011). Bioremediation potential of three acclimated bacteria with reference to heavy metal removal from waste. International Journal of Environmental Sciences, 2(2), 896-908. https://doi.org/10.6088/ijes.00202020048

Li, X. Y., Sun, J., Wang, H. H., Li, X., Wang, J., \& Zhang, H. W. (2017). Changes in the soil microbial phospholipid fatty acid profile with depth in three soil types of paddy fields in China. Geoderma, 290, 69-74. https://doi.org/10.1016/j.geoderma.2016.11.006

Li, Z. G., Feng, X. B., Li, G. H., Bi, X. Y., Sun, G. Y., Zhu, J. M., \& Wang, J. X. (2011). Mercury and other metal and metalloid soil contamination near a $\mathrm{Pb} / \mathrm{Zn}$ smelter in east Hunan province, China. Applied Geochemistry, 26(2), 160-166. https://doi.org/10.1016/j.apgeochem.2010.11.014

Liu, H., Zhang, B. G., Xing, Y., \& Hao, L. T. (2016). Behavior of dissolved organic carbon sources on the microbial reduction and precipitation of vanadium(v) in groundwater. $R S C$ Advances, 6, 97253-97258. https://doi.org/10.1039/c6ra19720e

Liu, H., Zhang, B. G., Yuan, H. Y., Cheng, Y. T., Wang, S., \& He, Z. (2017). Microbial reduction of vanadium $(\mathrm{V})$ in groundwater: Interactions with coexisting common electron acceptors and analysis of microbial community. Environmental Pollution, 231, 1362-1369. https://doi.org/10.1016/j.envpol.2017.08.111

Luo, X. S., Zeng, X. C., He, Z. C., Lu, X. L., Yuan, J., Shi, J. J., \& Wang, Y. X. (2014). Isolation and characterization of a radiation-resistant bacterium from Taklamakan Desert showing potent ability to accumulate Lead (II) and considerable potential for bioremediation of 
radioactive wastes. Ecotoxicology, 23(10), 1915-1921. https://doi.org/10.1007/s10646-014$1325-4$

Ma, C., Yu, Z., Lu, Q., Zhuang, L., \& Zhou, S. G. (2015). Anaerobic humus and Fe(III) reduction and electron transport pathway by a novel humus-reducing bacterium, Thauera humireducens SgZ-1. Applied microbiology and biotechnology, 99(8), 3619-3628. https://doi.org/10.1007/s00253-014-6254-x

Min, X. B., Wang, Y. Y., Chai, L. Y., Yang, Z. H., \& Liao, Q. (2017). High-resolution analyses reveal structural diversity patterns of microbial communities in Chromite Ore Processing Residue (COPR) contaminated soils. Chemosphere, 183, 266-276. https://doi.org/10.1016/j.chemosphere.2017.05.105

Mirazimi, S. M. L., Abbasalipour, Z., \& Rashchi, F. (2015). Vanadium removal from LD converter slag using bacteria and fungi. Journal of Environmental Management, 153, 144-151. https://doi.org/10.1016/j.jenvman.2015.02.008

Mohapatra, R. K., Parhi, P. K., Thatoi, H., \& Panda, C. R. (2017). Bioreduction of hexavalent chromium by Exiguobacterium indicum strain MW1 isolated from marine water of Paradip Port, Odisha, India. Chemistry and Ecology, 33(2), 114-130. https://doi.org/10.1080/02757540.2016.1275586

Moore, E. K., Hao, J., Prabhu, A., Zhong, H., Jelen, B. I., Meyer, M., Hazen, R. M. \& Falkowski, P. G. (2018). Geological and chemical factors that impacted the biological utilization of cobalt in the Archean Eon. Journal of Geophysical Research: Biogeosciences, 123. https://doi.org/10.1002/2017JG004067

Nedrich, S. M., Chappaz, A., Hudson, M. L., Brown, S. S., \& Burton, G. A. J. (2018). Biogeochemical controls on the speciation and aquatic toxicity of vanadium and other metals in sediments from a river reservoir. Science of The Total Environment, 612, 313-320. https://doi.org/10.1016/j.scitotenv.2017.08.141

Ortiz-Bernad, I., Anderson, R. T., Vrionis, H. A., \& Lovley, D. R. (2004). Vanadium respiration by Geobacter metallireducens: Novel strategy for in situ removal of vanadium from groundwater. Applied and Environmental Microbiology, 70(5), 3091-3095. https://doi.org/10.1128/AEM.70.5.3091-3095.2004

Peng, Q. A., Shaaban, M., Wu, Y. P., Hu, R. G., Wang, B. Y., \& Wang, J. (2016). The diversity of iron reducing bacteria communities in subtropical paddy soils of China. Applied Soil Ecology, 101(4), 20-27. https://doi.org/10.1016/j.apsoil.2016.01.012

Polti, M. A., Aparicio, J. D., Benimeli, C. S., \& Amoroso, M. J. (2014). Simultaneous bioremediation of $\mathrm{Cr}(\mathrm{VI})$ and lindane in soil by actinobacteria. International Biodeterioration \& Biodegradation, 88(2), 48-55. https://doi.org/10.1016/j.ibiod.2013.12.004

Pourret, O., Dia, A., Gruau, G., Davranche, M., \& Coz, M. B. (2012). Assessment of vanadium distribution in shallow groundwaters. Chemical Geology, 294-295(3), 89-102. https://doi.org/10.1016/j.chemgeo.2011.11.033

Puopolo, G., Tomada, S., Sonego, P., Moretto, M., Engelen, K., Perazzolli, M., \& Pertot, I. (2016). The Lysobacter capsici AZ78 genome has a gene pool enabling it to interact successfully with phytopathogenic microorganisms and environmental factors. Frontiers in microbiology, 7(780), 96. https://doi.org/10.3389/fmicb.2016.00096 
Qiu, R., Zhang, B. G., Li, J. X., Lv, Q., Wang, S., \& Gu, Q. (2017). Enhanced vanadium (V) reduction and bioelectricity generation in microbial fuel cells with biocathode. Journal of Power Sources, 359, 379-383. https://doi.org/10.1016/j.jpowsour.2017.05.099

Qu, L., Xie, Y. Y., Lu, G. N., Yang, C. F., Zhou, J. N., Yi, X. Y., \& Dang, Z. (2016). Distribution, fractionation, and contamination assessment of heavy metals in paddy soil related to acid mine drainage. Paddy and Water Environment, 15, 553-562. https://doi.org/10.1007/s10333-016-0572-9

Raghu, G., Balaji, V., Venkateswaran, G., Rodrigue, A., \& Maruthi Mohan, P. (2008). Bioremediation of trace cobalt from simulated spent decontamination solutions of nuclear power reactors using E. coli expressing NiCoT genes. Applied Microbiology \& Biotechnology, 81(3), 571-578. https://doi.org/10.1007/s00253-008-1741-6

Ran, J., Wang, D. J., Wang, C., Zhang, G., \& Zhang, H. L. (2015). Heavy metal contents, distribution, and prediction in a regional soil-wheat system. Science of the Total Environment, 544, 422-431. https://doi.org/10.1016/j.scitotenv.2015.11.105

Repert, D. A., Underwood, J. C., Smith, R. L., \& Song, B. (2014). Nitrogen cycling processes and microbial community composition in bed sediments in the Yukon River at Pilot Station. Journal of Geophysical Research: Biogeosciences, 119, 2328-2344. https://doi.org/doi:10.1002/2014JG002707

Rivas-Castillo, A., Orona-Tamayo, D., Gómez-Ramírez, M., \& Rojas-Avelizapa, N. G. (2017). Diverse molecular resistance mechanisms of Bacillus megaterium, during metal removal present in a spent catalyst. Biotechnology and Bioprocess Engineering, 22(3), 296-307. https://doi.org/10.1007/s12257-016-0019-6

Rowell, P., James, W., Smith, W. L., Handley, L. L., \& Scrimgeour, C. M. (1998). ${ }^{15} \mathrm{~N}$ discrimination in molybdenum- and vanadium-grown $\mathrm{N}_{2}$-fixing Anabaena variabilis and Azotobacter vinelandii. Soil Biology and Biochemistry, 30(14), 2177-2180. https://doi.org/10.1016/S0038-0717(98)00066-2

Shaheen, S. M., \& Rinklebe, J. (2018). Vanadium in thirteen different soil profiles originating from Germany and Egypt: Geochemical fractionation and potential mobilization. Applied Geochemistry, 88, 288-301. https://doi.org/10.1016/j.apgeochem.2017.02.010

Shaheen, S. M., Rinklebe, J., Frohne, T., White, J. R., \& DeLaune, R. D. (2016). Redox effects on release kinetics of arsenic, cadmium, cobalt, and vanadium in Wax Lake Deltaic freshwater marsh soils. Chemosphere, 150, 740-748. https://doi.org/10.1016/j.chemosphere.2015.12.043

Shaheen, S. M., Rinklebe, J., Rupp, H., \& Meissner, R. (2014). Lysimeter trials to assess the impact of different flood-dry-cycles on the dynamics of pore water concentrations of As, $\mathrm{Cr}$, Mo and V in a contaminated floodplain soil. Geoderma, 228-229, 5-13. https://doi.org/ 10.1016/j.geoderma.2013.12.030

Solisio, C., Lodi, A., Converti, A., \& Borghi, M. D. (1998). Cadmium, zinc and chromiu-m(III) removal from aqueous solutions by Zoogloea ramigera. Chemical and Biochemical Engineering Quarterly, 12(1), 45-49.

Stuart, R. K., Brahamsha, B., Busby, K., \& Palenik, B. (2013). Genomic island genes in a coastal marine Synechococcus strain confer enhanced tolerance to copper and oxidative stress. The ISME Journal, 7(6), 1139-1149. https://doi.org/10.1038/ismej.2012.175 
Teng, Y. G., Ni, S. J., Zhang, C. J., Wang, J. S., Lin, X. Y., \& Huang, Y. (2006). Environmental geochemistry and ecological risk of vanadium pollution in Panzhihua mining and smelting area, Sichuan, China. Chinese Journal of Geochemistry, 25, 379-385. https://doi.org/10.1007/s11631-006-0378-3

Teng, Y. G., Yang, J., Sun, Z. J., Wang, J. S., Zuo, R., \& Zheng, J. Q. (2011). Environmental vanadium distribution, mobility and bioaccumulation in different land-use districts in Panzhihua Region, SW China. Environmental Monitoring and Assessment, 176(1-4), 605-620. https://doi.org/10.1007/s10661-010-1607-0

Timofeeva, Y. O., Kosheleva, Y., Semal, V., \& Burdukovskii, M. (2018). Origin, baseline contents, and vertical distribution of selected trace lithophile elements in soils from nature reserves, Russian Far East. Journal of Soils and Sediments, 18(3), 968-982. https://doi.org/10.1007/s11368-017-1847-5

Tokalığlu, Ş., \& Kartal, Ş. (2005). Comparison of metal fractionation results obtained from single and BCR sequential extractions. Bulletin of Environmental Contamination \& Toxicology, 75(1), 180-188. https://doi.org/10.1007/s00128-005-0736-6

Undabarrena, A., Ugalde, J. A., Seeger, M., \& Camara, B. (2017). Genomic data mining of the marine actinobacteria Streptomyces sp. H-KF8 unveils insights into multi-stress related genes and metabolic pathways involved in antimicrobial synthesis. PeerJ, 5(2), e2912. https://doi.org/ 10.7717/peerj.2912

Ure, A. M., Quevauviller, P., Muntau, H., \& Griepink, B. (1993). Speciation of heavy metals in soils and sediments. An account of the improvement and harmonization of extraction techniques undertaken under the auspices of the BCR of the Commission of the European Communities. International Journal of Environmental Analytical Chemistry, 51(1-4), 135151. https://doi.org/10.1080/03067319308027619

Vicars, W. C., \& Sickman, J. O. (2011). Mineral dust transport to the Sierra Nevada, California: Loading rates and potential source areas. Journal of Geophysical Research, 116, G01018. https://doi.org/10.1029/2010JG001394

Vryzas, Z., Papadakis, E. N., Oriakli, K., Moysiadis, T. P., \& Papadopoulou-Mourkidou, E. (2012). Biotransformation of atrazine and metolachlor within soil profile and changes in microbial communities. Chemosphere, 89(11), 1330-1338. https://doi.org/10.1016/j.chemosphere.2012.05.087

Wang, C. Y., Wang, F., Hong, Q., Zhang, Y. P., Kengara, F. O., Li, Z. B., \& Jiang, X. (2013). Isolation and characterization of a toxic metal-tolerant Phenanthrene-degrader Sphingobium sp. in a two-liquid-phase partitioning bioreactor (TPPB). Environmental Earth Sciences, 70(4), 1765-1773. https://doi.org/10.1007/s12665-013-2264-8

Wang, L., Teng, Y. G., Wang, J. S., Xiao, J., Zhang, Q. Q., \& Jiao, X. D. (2009). Distribution and chemical speciation of vanadium in downstream of Panzhihua tailing dam. Environmental Chemistry, 28(3), 445-448.

Wang, S., Zhang, B. G., Diao, M. H., Shi, J. X., Jiang, Y. F., Cheng, Y. T., \&Liu, H. (2018). Enhancement of synchronous bio-reductions of vanadium (V) and chromium (VI) by mixed anaerobic culture. Environmental Pollution, 242, 249-256. https://doi.org/10.1016/j.envpol.2018.06.080 
Wilson, S. A., \& Weber, J.H. (1979). An EPR study of the reduction of vanadium(V) to vanadium(IV) by fulvic acid. Chemical Geology, 26, 345-354. https://doi.org/10.1016/00092541(79)90056-1

Wright, M. T., \& Belitz, K. (2010). Factors controlling the regional distribution of vanadium in groundwater. Groundwater, 48(4), 515-525. https://doi.org/10.1111/j.1745-6584.2009.00666.x

Wright, M. T., Stollenwerk, K. G., \& Belitz, K. (2014). Assessing the solubility controls on vanadium in groundwater, northeastern San Joaquin Valley, CA. Applied Geochemistry, 48(3), 41-52. https://doi.org/10.1016/j.apgeochem.2014.06.025

Xiao, X. Y., Wang, M. W., Zhu, H. W., Guo, Z. H., Han, X. Q., \& Zeng, P. (2017). Response of soil microbial activities and microbial community structure to vanadium stress. Ecotoxicology and environmental safety, 142, 200-206. https://doi.org/10.1016/j.ecoenv.2017.03.047

Xu, J., Veeramani, H., Qafoku, N. P., Singh, G., Riquelme, M. V., Pruden, A., Kukkadapu, R. K., Gartman, B. N., \& Hochella Jr, M. F. (2017). Efficacy of acetate-amended biostimulation for uranium sequestration: Combined analysis of sediment/groundwater geochemistry and bacterial community structure. Applied Geochemistry, 78, 172-185. https://doi.org/10.1016/j.apgeochem.2016.12.024

Xu, N., Qiu, G. W., Lou, W. J., Price, N. M., Qiu, B. S., \& Jiang, H. B. (2016). Identification of an iron permease, cFTR1, in cyanobacteria involved in the iron reduction/re-oxidation uptake pathway. Environmental Microbiology, 18(12), 5005-5017. https://doi.org/10.1111/14622920.13464

Yang, J. Y., Huang, J. H., Lazzaro, A., Tang, Y., \& Zeyer, J. (2014a). Response of soil enzyme activity and microbial community in vanadium-loaded soil. Water Air \& Soil Pollution, 225, 2012-2021. https://doi.org/10.1007/s11270-014-2012-Z

Yang, J. Y., Tang, Y., Yang, K., Rouff, A. A., Elzinga, E. J., \& Huang, J. H. (2014b). Leaching characteristics of vanadium in mine tailings and soils near a vanadium titanomagnetite mining site. Journal of Hazardous Materials, 264(2), 498-504. https://doi.org/10.1016/j.jhazmat.2013.09.063

Yang, J., Teng, Y. G., Wu, J., Chen, H. Y., Wang, G. Q., Song, L. T., \& Zhai, Y. Z. (2017). Current status and associated human health risk of vanadium in soil in China. Chemosphere, 171, 635-643. https://doi.org/10.1016/j.chemosphere.2016.12.058

Yelton, A. P., Williams, K. H., Fournelle, J., Wrighton, K. C., Handley, K. M., \& Banfield, J. F. (2013). Vanadate and acetate biostimulation of contaminated sediments decreases diversity, selects for specific taxa, and decreases aqueous $\mathrm{V}^{5+}$ concentration. Environmental Science \& Technology, 47(12), 6500-6509. https://doi.org/10.1021/es4006674

Yu, H. L., He, N. P., Wang, Q. F., Zhu, J. X., Gao, Y., Zhang, Y. H., \& Yu, G. R. (2017). Development of atmospheric acid deposition in China from the 1990s to the 2010s. Environmental Pollution, 231, 182-190. https://doi.org/10.1016/j.envpol.2017.08.014

Zhang, B. G., Feng, C. P., Ni, J. R., Zhang, J., \& Huang, W. L. (2012). Simultaneous reduction of vanadium (V) and chromium (VI) with enhanced energy recovery based on microbial fuel cell technology. Journal of Power Sources, 204(1), 34-39. https://doi.org/10.1016/j.jpowsour.2012.01.013 
Zhang, B. G., Hao, L. T., Tian, C. X., Yuan, S. H., Feng, C. P., Ni, J. R., \& Borthwick, A. G. (2015a). Microbial reduction and precipitation of vanadium (V) in groundwater by immobilized mixed anaerobic culture. Bioresource Technology, 192, 410-417. https://doi.org/10.1016/j.biortech.2015.05.102

Zhang, B. G., Qiu, R., Lu, L., Chen, X., He, C., Lu, J. P., \& Ren, Z.J. (2018). Autotrophic Vanadium(V) bioreduction in groundwater by elemental sulfur and zerovalent iron. Environmental Science \& Technology, in press. https://doi.org/ 10.1021/acs.est.8b01317

Zhang, B. G., Tian, C. X., Liu, Y., Hao, L. T., Liu, Y., Feng, C. P., \& Wang, Z. L. (2015b). Simultaneous microbial and electrochemical reductions of vanadium (V) with bioelectricity generation in microbial fuel cells. Bioresource Technology, 179, 91-97. https://doi.org/10.1016/j.biortech.2014.12.010

Zhang, B. G., Zhao, H. Z., Shi, C. H., Zhou, S. G., \& Ni, J. R. (2009). Simultaneous removal of sulfide and organics with vanadium (V) reduction in microbial fuel cells. Journal of Chemical Technology \& Biotechnoly, 84(12), 1780-1786. https://doi.org/10.1002/jctb.2244

Zhang, B. G., Zou, S. Q., Cai, R. Q., Li, M., \& He, Z. (2018). Highly-efficient photocatalytic disinfection of Escherichia coli under visible light using carbon supported Vanadium Tetrasulfide nanocomposites. Applied Catalysis B: Environmental, 224, 383-393. https://doi.org/10.1016/j.apcatb.2017.10.065

Zhang, J., Dong, H., Zhao, L., McCarrick, R., \& Agrawal, A. (2014). Microbial reduction and precipitation of vanadium by mesophilic and thermophilic methanogens. Chemical Geology, 370(4), 29-39. https://doi.org/10.1016/j.chemgeo.2014.01.014

Zheng, S. X., Su, J., Wang, L., Yao, R., Wang, D., Deng, Y. J., \& Wang, R. (2014). Selenite reduction by the obligate aerobic bacterium Comamonas testosteroni $\mathrm{S} 44$ isolated from a metal-contaminated soil. BMC Microbiology, 14(1), 1-14. https://doi.org/10.1186/s12866-0140204-8 
Table 1. Chemical speciation of vanadium in solid matrices based on modified three-step Community Bureau of Reference (BCR) sequential extraction procedure. MP: mining plant; CO: concentrator; SM: smelter; TR: tailing reservoir; JS: Jinsha River.

\begin{tabular}{ccccccccc}
\hline & $\begin{array}{c}\text { Acid- } \\
\text { soluble (\%) }\end{array}$ & SD & $\begin{array}{c}\text { Reducible } \\
\mathbf{( \% )}\end{array}$ & SD & $\begin{array}{c}\text { Oxidizable } \\
\mathbf{( \% )}\end{array}$ & SD & $\begin{array}{c}\text { Residual } \\
\mathbf{( \% )}\end{array}$ & SD \\
\hline MP-SL0 & $1.97 \pm 0.52$ & a & $3.24 \pm 1.02$ & a & $5.83 \pm 0.59$ & a & $89.0 \pm 3.32$ & $\mathrm{a}$ \\
CO-SL0 & $1.39 \pm 0.59$ & a & $9.54 \pm 1.05$ & b & $8.79 \pm 0.12$ & a & $80.3 \pm 4.21$ & $\mathrm{~b}$ \\
SM-SL0 & $7.48 \pm 0.15$ & b & $18.7 \pm 2.02$ & c & $19.3 \pm 2.56$ & $\mathrm{~b}$ & $54.5 \pm 1.21$ & $\mathrm{c}$ \\
TR-SL0 & $10.9 \pm 0.95$ & $\mathrm{c}$ & $16.0 \pm 0.25$ & $\mathrm{c}$ & $16.2 \pm 0.56$ & $\mathrm{~b}$ & $56.9 \pm 1.22$ & $\mathrm{~d}$ \\
$p$ & $<0.001$ & & $<0.001$ & & $<0.001$ & & $<0.001$ & \\
TR-SD0 & $7.61 \pm 0.23$ & $\mathrm{a}$ & $15.6 \pm 0.26$ & $\mathrm{a}$ & $16.3 \pm 0.99$ & $\mathrm{a}$ & $60.5 \pm 2.25$ & $\mathrm{a}$ \\
JS-SD0 & $0.20 \pm 0.08$ & $\mathrm{~b}$ & $5.73 \pm 1.21$ & $\mathrm{~b}$ & $2.42 \pm 0.18$ & $\mathrm{~b}$ & $91.7 \pm 3.79$ & $\mathrm{~b}$ \\
TR-TL0 & $1.67 \pm 0.25$ & $\mathrm{c}$ & $6.08 \pm 0.12$ & $\mathrm{~b}$ & $10.4 \pm 0.21$ & $\mathrm{c}$ & $81.8 \pm 2.15$ & $\mathrm{c}$ \\
Ore & $0.07 \pm 0.01$ & $\mathrm{~b}$ & $7.95 \pm 0.98$ & $\mathrm{c}$ & $10.5 \pm 1.25$ & $\mathrm{c}$ & $81.5 \pm 4.15$ & $\mathrm{c}$ \\
$p$ & $<0.001$ & & $<0.01$ & & $<0.001$ & & $<0.001$ & \\
TR-S1 & $5.58 \pm 0.15$ & $\mathrm{a}$ & $8.98 \pm 0.25$ & $\mathrm{a}$ & $25.2 \pm 2.56$ & $\mathrm{a}$ & $60.2 \pm 3.79$ & $\mathrm{a}$ \\
TR-S2 & $6.36 \pm 0.59$ & $\mathrm{ab}$ & $9.05 \pm 0.26$ & $\mathrm{a}$ & $26.3 \pm 0.12$ & $\mathrm{a}$ & $58.3 \pm 2.15$ & $\mathrm{ab}$ \\
TR-S3 & $4.78 \pm 0.52$ & $\mathrm{ac}$ & $8.54 \pm 2.02$ & $\mathrm{a}$ & $25.9 \pm 0.56$ & $\mathrm{a}$ & $60.7 \pm 1.22$ & $\mathrm{a}$ \\
TR-S4 & $2.91 \pm 0.15$ & $\mathrm{~b}$ & $8.18 \pm 1.05$ & $\mathrm{a}$ & $26.0 \pm 0.99$ & $\mathrm{a}$ & $62.9 \pm 2.25$ & $\mathrm{a}$ \\
TR-S5 & $2.87 \pm 0.95$ & $\mathrm{~b}$ & $9.32 \pm 1.02$ & $\mathrm{a}$ & $26.2 \pm 0.59$ & $\mathrm{a}$ & $61.6 \pm 3.32$ & $\mathrm{a}$ \\
TR-S6 & $0.53 \pm 0.23$ & $\mathrm{c}$ & $8.15 \pm 2.02$ & $\mathrm{a}$ & $25.8 \pm 2.56$ & $\mathrm{a}$ & $65.5 \pm 1.21$ & $\mathrm{ac}$ \\
$p$ & $<0.001$ & & $>0.05$ & & $>0.05$ & & $>0.05$ & \\
\hline
\end{tabular}

SD: significant difference 


\section{Figure Captions}

Fig. 1. Vanadium distributions in multiple matrices in Panzhihua region, China. (a) surface soils and sediments $(p<0.001)$, (b) vertical soil profile $(p<0.001)$, and (c) groundwater and surface water $(p<0.001)$. Error bars indicate standard deviation.

Fig. 2. Microbial community compositions revealed by high-throughput sequencing in multiple matrices at genus level. (a) surface soils; (b) vertical soil profile; (c) groundwater; and (d) surface water and sediments.

Fig. 3. NMDS plots and RDA of microbial communities. (a) NMDS plots for all original samples; RDA for (b) solid samples and (c) aqueous samples.

Fig. 4. Dynamics of $V(V)$ in all cultivated systems with chemical speciation and product examinations. $\mathrm{V}(\mathrm{V})$ removals in three consecutive cycles in (a) soil-inoculated system and (b) water-inoculated system; (c) chemical speciation of vanadium in soils after cultivation; and (d) XPS analysis of generated precipitates in water-inoculated system. A typical cycle comprises 72 $\mathrm{h}$ for soil-inoculated system and $12 \mathrm{~h}$ for water-inoculated system (see Section 2.3). Red arrows indicate the replacement of mineral salt solution at the beginning of each cycle. The chemical speciation and XPS data are collected at the end of the incubation period.

Fig. 5. Accumulated functional species related to detoxifying $V(V)$ at genus level in different cultivated systems. (a) soil-inoculated system; (b) water-inoculated system. 